\title{
El médico radiólogo como asesor paraclínico
}

\section{The radiologist as a paraclinical advisor}

Bernardo Boleaga-Durán ${ }^{1,2 *}$

${ }^{1}$ Práctica Privada, Mérida, Yucatán; ${ }^{2}$ Radiología e Imagen, Academia Mexicana de Cirugía, Ciudad de México. México

En el arduo camino que recorren los estudiantes de Medicina para obtener el título de Médico Cirujano, en este magnífico país mexicano, se establece la conjunción de conocimientos obtenidos desde el inicio escolar hasta la culminación de la difícil experiencia para convertirse en médico cirujano. La obtención de este grado académico y de su registro en la Dirección General de Profesiones de la Secretaría de Educación Pública (SEP) les permite laborar profesionalmente como médico cirujano general para conseguir el primer contacto profesional formal con un paciente, cuyo acontecimiento como médico general, le otorga la oportunidad de conjuntar los conocimientos adquiridos, mediante el intenso estudio, con su inicial experiencia como médico, con conocimientos usualmente básicos, utilizados para procurar comprender la problemática clínica del paciente y definir las posibilidades diagnósticas que podrá afrontar con un adecuado esquema terapéutico.

El médico recién egresado de la facultad de medicina se establece inicialmente como

médico general, amparado por el título de Médico Cirujano que otorgan las facultades de medicina de diversas universidades nacionales. El concepto se ha modificado y actualmente se identifica como licenciatura. La habilidad clínica del médico general suele incrementarse progresivamente al establecer contacto con pacientes. Paradójicamente, cuando opta por intentar elevar su grado académico, a corto plazo se concentra su horizonte requerido de conocimientos, en un área específica, identificada como «especialidad médica». Sin embargo, en la formación de un médico radiólogo, durante la etapa de residencia médica, se requiere incrementar el horizonte de conocimientos sobre anatomía, fisiología y patología de todo el cuerpo humano, para optimizar la comprensión de los hallazgos en las imágenes obtenidas con los diferentes métodos de imagen diagnóstica. En los residentes de radiología, el sustrato básico de conocimientos como médico general, se suma al esfuerzo personal y de grupo, realizado durante el tiempo invertido en la especialidad de radiología e imagen, 
incorporando la evocación de los conceptos aprendidos y el conocimiento de nuevos conceptos complementarios sobre la fisiología y la patología de los aparatos o sistemas del cuerpo humano, profundizado con el intenso aprendizaje individual y el fatigante desempeño como médico residente. La conjunción de experiencias personales integra las aportaciones diagnósticas de los diversos métodos diagnósticos, con variada especificidad y sensibilidad diagnóstica.

En la evaluación de los diversos procesos patológicos que afectan al ser humano, de cualquier etiología, la información que aportan los procedimientos tradicionales de diagnóstico por imágenes, como las radiografías simples, la telerradiografía de tórax, la angiografía y la mielografía, puede ser complementada $y$, en algunos casos, substituida por otros procedimientos, como la ultrasonografía, tomografía computarizada de múltiples detectores (TCMD), imagen por resonancia magnética (IRM), angiografía cerebral con sustracción digital (ASD) y tomografía por emisión de positrones con imágenes fusionadas con tomografía computarizada (PET/TC) o con RM (PET/RM). Recientemente se ha incorporado exitosamente la asociación de tomografía computada de fotón único (SPECT) tanto a las imágenes de TC como a las de IRM. Las posibilidades diagnósticas aportadas por la evaluación clínica, como el interrogatorio, directo o indirecto, la inspección, la percusión, la palpación y la auscultación, los signos y síntomas de cada paciente, el tiempo de evolución del padecimiento, su modo de presentación y los hallazgos en la exploración clínica, representan elementos importantes para elegir adecuadamente el procedimiento de imagen diagnóstica con mayor sensibilidad y especificidad, en ocasiones apoyado con el empleo adicional de algún medio de contraste.

Con lineamientos legales establecidos por el Consejo Mexicano de Radiología e Imagen, A. C., se confiere al médico radiólogo la certificación en Radiología e Imagen que le otorga facultades para practicar su especialidad, suscribiendo legalmente interpretaciones de los procedimientos diagnósticos, investido con la adecuada autorización para llevar a cabo sus actividades profesionales con tecnología de punta que utiliza diversos medios físicos, como:

- Radiación ionizante: Radiología convencional, mastografía, angiografía, flebografía, TC y densitometría.

- Combinación de campos magnéticos con señales de radiofrecuencia: IRM.

- Ultrasonografía: Se ha convertido en un valioso elemento diagnóstico por su sensibilidad, accesibilidad y bajo costo.

- Entre los más recientes métodos de diagnóstico por imágenes se incorporó la medicina nuclear, con procedimientos que utilizan radioisótopos para evaluar la funcionalidad de diversos tejidos corporales, como la SPECT y la PET. En estos métodos de medicina nuclear se requiere la participación interpretativa de médicos certificados por el Consejo de Medicina Nuclear. Las interpretaciones de la PET, integrada a la TC o a la IRM, requieren la participación conjunta del médico radiólogo certificado, avalada con su número de cédula profesional.

La certeza diagnóstica depende de la experiencia y de la habilidad del médico radiólogo, empleando los hallazgos de las imágenes diagnósticas, integrados adecuadamente a la información clínica, cuya congruencia suele 
ser el resultado de una consistente colaboración interdisciplinaria con los médicos que solicitan el procedimiento diagnóstico. Entre los objetivos básicos del diagnóstico por imagen se encuentra la definición de la posible variedad histológica de la lesión o las lesiones en estudio. Esta precisión no debe realizarse de forma aleatoria ni casual, por lo que es aconsejable obtener el máximo de información clínica de cada caso y conjuntar los elementos obtenidos por imagen para procurar la obtención de un factor etiológico y definir una o varias posibilidades diagnósticas, acordes con los elementos clínicos. Los esfuerzos para utilizar estos métodos diagnósticos en la evaluación de los procesos patológicos convierten al médico radiólogo en un verdadero «experto» en su área, aplicando con su experiencia los conocimientos anatómicos y clínicos inherentes al área de especialización, como la neurología, la neumología, el tubo digestivo, la glándula mamaria, los senos paranasales, etc. La «habilidad profesional» del médico radiólogo combina los conocimientos anatómicos, fisiológicos y patológicos mediante la radiología convencional, la TC, la IRM, la PET, la ultrasonografía, la mastografía, la angiografía y la flebografía, entre muchos otros procedimientos diagnósticos. Esta habilidad profesional convierte al médico radiólogo en un asesor profesional y colaborador interdisciplinario, frente a los médicos generales y especialistas de diversas áreas médicas.

En esta forma, la constante renovación y superación técnica de la especialidad de radiología e imagen se ha posicionado en forma progresiva y permanente en un lugar privilegiado en la estructura médica para ofrecer el diagnóstico diferencial oportuno, con el objetivo de favorecer la adecuada terapéutica de múltiple patología como un valioso y activo apoyo paraclínico a las diversas áreas médicas que requieren del conocimiento y la experiencia del médico radiólogo. En las últimas décadas, el intervencionismo realizado por médicos radiólogos ha permitido que participen activamente con notable éxito en la toma decisiones terapéuticas, influyendo en la evolución clínica de múltiple patología, abatiendo los costos terapéuticos y reduciendo la estancia hospitalaria, en la mayoría de los casos. La evolución tecnológica de algunos procedimientos y el interés por ciertas especialidades médicas ha propiciado la afinidad de algunos médicos radiólogos para dedicarse exclusivamente a especialidades como neurorradiología, radiología pediátrica, mastografía, ultrasonografía, etc.

En muchos hospitales, clínicas médicas y departamentos de radiología e imagen, la interconsulta con el médico radiólogo, como asesor paraclínico, en casos con diagnóstico difícil, determina la ruta diagnóstica y la definición terapéutica de muchos casos, colaborando e interactuando activamente con los médicos tratantes de los pacientes, mediante comentarios y sugerencias, en favor de la salud de los pacientes, con participación profesional multidisciplinaria, en esta noble y digna especialidad médica. 